\title{
ENVIRONMENTAL VARIABLES INFLUENCING EXCLUSIVE BREASTFEEDING AMONG MOTHERS ATTENDING POSTNATAL CLINICS IN A TERTIARY HEALTH INSTITUTION
}

\author{
Nwankwo Ifeyinwa Patience ${ }^{1}$ and Ilo Ifeyinwa Clementine ${ }^{2^{*}}$ \\ ${ }^{1}$ Nnamdi Azikiwe University Teaching Hospital, Nnewi \\ ${ }^{2}$ Department of Nursing Science, Nnamdi Azikiwe University, Nnewi Campus \\ *Corresponding Email: ci.ilo@ unizik.edu.ng
}

Cite this article:

Nwankwo I.P., Ilo I.C. (2021), Environmental Variables Influencing Exclusive

Breastfeeding Among Mothers Attending Postnatal Clinics in A Tertiary Health Institution. African Journal of Health, Nursing and Midwifery 4(6), 71-83. DOI:

10.52589/AJHNM-

P79U9MFY.

\section{Manuscript History}

Received: 29 Aug 2021

Accepted: 19 Oct 2021

Published: 18 Nov 2021

Copyright $\odot 2020$ The Author(s). This is an Open Access article distributed under the terms of Creative Commons AttributionNonCommercial-NoDerivatives 4.0 International (CC BY-NC-ND 4.0 ), which permits anyone to share, use, reproduce and redistribute in any medium, provided the original author and source are credited.
ABSTRACT: The current WHO/UNICEF feeding recommends that breastfeeding with good nutrition is essential to achieving the UN sustainable development goals. This study was carried out to assess the environmental variables influencing exclusive breastfeeding of infants aged 0-6 months in Nnamdi Azikiwe University Teaching Hospital Nnewi, Anambra State, Nigeria. Three objectives guided the study. Cross sectional descriptive survey design was used for the study. The instrument for data collection was a structured questionnaire which was validated by experts and was administered to four hundred (400) post natal women of child bearing age who were randomly selected. The data collected were analyzed using statistical methods, which included mean, chi square, and t-test which were presented in frequencies and percentages. The result revealed that $44.7 \%$ of babies were exclusively breastfed while more than half (55.3\%) were not exclusively breastfed. The result of this study also showed that maternal education had a significant effect on their exclusive breastfeeding pattern $(P<0.05)$ as $65.9 \%$ of mothers who breastfed exclusively had up to tertiary education. An association was also found between the parity of mother and breastfeeding practices. This is because $46.3 \%$ of mothers who had three or more children breastfed their children exclusively. This study showed a positive association between place of delivery and breastfeeding practices. Place of delivery revealed a significant difference between the two groups as exclusive breastfeeding was observed in $95.5 \%$ babies delivered in government health facilities compared with $4.5 \%$ delivered at private health facilities. Health workers should educate the mothers about the benefit of exclusive breastfeeding. Some other factors found to prevent mothers from practicing exclusive breastfeeding were finance, 36 (16.3\%); personal reasons, 51 (20.1\%); lack of time as they have to go back to work, 72 (32.6\%); dissatisfaction, 40 (18.0\%); stress, 9 (4.0\%); baby's refusal, 7 (3.2\%); and pains, $6(2.7 \%)$.

KEYWORDS: Exclusive Breastfeeding, Maternal Education, Place of Delivery 


\section{INTRODUCTION}

Breastfeeding is the first step in life which ensures that infants and young children get a healthy and nutritious start to life. Breastfeeding is acknowledged as the optimal way to feed infants for the first six months by the national and many other health organizations (United Nations Children's Fund [UNICEF] 2006; World Health Organization [WHO], 2003). According to the American Academy of Pediatrics (AAP, 2005; WHO, 2014), there is strong evidence that infants receiving only breast milk with no other liquids or solids, known as exclusive breastfeeding (EBF), has many health benefits to mothers, babies, the environment and society. Exclusive breastfeeding also provides many maternal benefits such as reducing the chances of developing adverse health outcomes such as obesity and ovarian and breast cancer in mothers (Stevens, Hanson, Prasek \& Elliott, 2008; Thulier\& Mercer, 2009).

Despite its countless benefits, the continuation rates of EBF are still low (Silfverdal, 2011; Centers for Disease Control and Prevention [CDC], 2013; Dudenhausen, 2014). High infant mortality rates associated with diarrhoea, acute respiratory infections and poor responses to vaccinations that result from lack of exclusive breastfeeding (UNICEF, 2006) can greatly be reduced if exclusive breastfeeding of infants is encouraged. This is because human milk is the ideal nourishment for an infant's survival, growth and development as it contains all the nutrients, antibodies, hormones, immune factors and antioxidants an infant needs to thrive (UNICEF, 2006). The low prevalence and short duration of exclusive breastfeeding in previous studies have highlighted the need for more investigation into the problem of growth and development of these infants (Balkam, Cadwell \& Fein, 2011). Breastfeeding is widely practiced in Nigeria but exclusive breastfeeding rates vary (Okolo, Adewunmi \& Okonji, 2009). Some of the major factors identified which influence EBF in some communities in the country include - but are not limited to - attitudes of health workers and policies of health facilities on breastfeeding (Ukegbu, Ukegbu, Onyenoro\&Ubajiaka, 2011).

One of the key strategies in promoting breastfeeding in childbearing women is antenatal breastfeeding education (Jennifer, Elaine, Athena \& Virginia, 2013). Studies on breastfeeding concluded that women who failed to receive adequate support from healthcare professionals when faced with breastfeeding challenges were less likely to continue breastfeeding (CrossBarnet, Augustyn, Gross, Resnick \& Paige, 2012). Sholeye, Abosede and Salako (2014), in assessing the associated factors of breastfeeding among mothers of children less than two years of age in Sagamu, Southwest Nigeria, found out that about 25\% of the respondents were pressured by relatives to stop exclusive breastfeeding. Other personal reasons for not breastfeeding exclusively includebreast pain, a difficult work schedule, poorsupport from partners and perceived weight loss.

Another study done to examine the constraints to exclusive breastfeeding practice among breastfeeding mothers in Southwest Nigeria-Implications for Scaling Up by Agunbiade and Ogunleye (2012)-showed the major constraints to exclusive breastfeeding to bethe perception that babies continued to be hungry after breastfeeding (29\%), maternal health problems (26\%), fear of babies becoming addicted to breast milk (26\%), pressure from mother-in-law (25\%), pains in the breast $(25 \%)$, and the need to return to work $(24 \%)$. In addition, the qualitative findings showed that significant others played dual roles with consequences on breastfeeding practices. The desire to practice exclusive breastfeeding was often compromised shortly after child delivery. Poor feeding, inadequate support from husband and conflicting positions from significant others were dominant constraints. 
The poor indices of nutritional status of Nigerian children make it imperative to assess the level of exclusive breastfeeding within the study area which is a tertiary health facility and heavily patronized by pregnant women. It is worth carrying out this study to assess the environmental variables influencing exclusive breastfeeding among mothers attending postnatal clinics in Nnamdi Azikiwe University Teaching Hospital Nnewi, Anambra State. The findings of this study will hopefully be used in designing appropriate and effective breastfeeding intervention programmes aimed at providing insight for exclusive breastfeeding promotion, and provide the health workers with the knowledge and confidence on how to support mothers to successfully breastfeed their babies.

\section{METHODS AND MATERIALS}

This study used the cross-sectional descriptive survey design. This study was carried out in Nnamdi Azikiwe University Teaching Hospital (NAUTH) Nnewi, Anambra State among mothers and infants who attended the post natal clinic. These mothers were interviewed to get information on the environmental factors that may affect the practice of exclusive breastfeeding. The simple random sampling technique was used to select a sample size of 400 which was determined using the 'Yaro Yamane' formula for finite population. Data was collected using a researcher designed questionnaire on exclusive breastfeeding to elicit information from the mothers and their responses were recorded accordingly. The face and content validity of the researcher designed questionnaire was established by experts in nutrition and reproductive health. Split-half reliability method was used to determine the reliability of the instrument which yielded a coefficient reliability test result of 0.95 . Informed consent was obtained from the respondents and confidentiality was maintained. Institutional Ethical Clearance was sought for and obtained from the research and ethical committee of the Faculty of Health Sciences and Technology, Nnamdi Azikiwe University, Nnewi campus, Anambra State. Information concerning the environmental factors like the parity, occupation, mode of delivery, pattern of delivery and place of delivery were collected. The data collection lasted for a period of twenty-four weeks at the end of which a total of 400 mothers were interviewed. Data from the survey was statistically analyzed using the Statistical Package for Social Sciences (SPSS) (version 20). Inferential statistics and chisquare test were performed to compare the effects of different factors on exclusive breastfeeding practice. Chi-square statistic $\left(\chi^{2}\right)$ was used to establish whether relationships existed among the variables. Statistical significance was assumed for $\mathrm{P}<0.05$. Basic descriptive analysis was done using frequency distribution tables, charts and graphs. 


\section{RESULTS}

Table 1: Demographic characteristics of mothers

Age of the Mother

\section{Frequency Percent $\quad$ Total (\%)}

$<20$ years

21-25 years

26-30 years

31-35 years

$36-40$ years
29

98

138

95

40

15

28

109

248

171

229

76

143

181
7.2

34.5

23.7

10

400 (100)

\section{Occupation}

Housewife

Working class women

\section{Parity}

1

2

$>3$
3.8

7

27.2

62

400(100)

42.7

57.3

400(100)

19

35.7

45.3

400(100)

Results from table 1 regarding the socio- demographic variable of the mothers (respondents) show that $29(7.2 \%)$ of the respondents were <20 years, $98(24.5 \%)$ were $21-25$ years, 138 $(34.5 \%)$ were $26-30$ years, 95 (23.7\%) were $31-35$ years and $40(10 \%)$ were $36-40$ years. Respondents who had no formal education had 15 (3.8\%), 28 (7\%) had primary education, $109(27.2 \%)$ had secondary education and $248(62 \%)$ had tertiary education. Respondents who were housewives were $171(42.7 \%)$ while working class women were $229(57.3 \%)$. Respondents who had one child were 76 (19\%), those who had two children were 143 $(35.7 \%)$ and those who had three or more children were $181(45.3 \%)$. 
Table 4: Demographic characteristics of babies

\begin{tabular}{lccc}
\hline Gender & Frequency & Percent & Total (\%) \\
Female & & & \\
Male & 212 & 53 & $400(100)$ \\
& 188 & 47 & \\
Baby's current age & & & \\
$0-2$ months & 119 & 29.7 & \\
3-4 months & 130 & 32.5 & $400(100)$ \\
5-6 months & 151 & 37.7 & \\
Mode of delivery & & & \\
Vaginal Birth & 309 & 77.3 & \\
Caesarean Section & 91 & 22.7 & \\
& & & $400(100)$ \\
Place of birth & 345 & 86.3 & \\
Government Health Facility & 55 & 13.7 & \\
Private Health Facility & & & $400(100)$ \\
& & & \\
Pattern of Breastfeeding & 179 & 44.7 & \\
Exclusive Breastfeeding & 221 & 55.3 & $400)$ \\
Non Exclusive Breastfeeding & &
\end{tabular}

Results from table 2 show the demographic characteristics of the babies. Respondents showed that $212(53 \%)$ were females and $188(47 \%)$ were males. Respondents showed that $119(29.7 \%)$ were between 0-2 months, 130 (32.5\%) were between 3-4 months while 151 (37.7\%) were between 5-6 months. Respondents who had vaginal delivery were 309 (77.3\%) while those who delivered through cesarean section were 91 (22.7\%). Results showed that $345(86.3 \%)$ gave birth in the government health facility while $55(13.7 \%)$ gave birth at a private health facility. The respondents' pattern of breastfeeding showed that $179(44.7 \%)$ of the babies were exclusively breastfed while more than half $221(55.3 \%)$ were not exclusively breastfed.

\section{Objective 1:}

To find out the influence of mothers' socio-demographic variables on the pattern of breastfeeding of infants aged 0-6 months in Nnamdi Azikiwe University Teaching Hospital Nnewi, Anambra State. 
Table 3: Breastfeeding pattern according to mothers' demographic characteristics

\begin{tabular}{|c|c|c|c|c|c|}
\hline \multirow[t]{3}{*}{ Parameters } & \multicolumn{2}{|c|}{ Breastfeeding pattern } & \multirow[t]{3}{*}{$\mathbf{X}^{2}$} & \multirow[t]{3}{*}{ Df } & \multirow[t]{3}{*}{ P-value } \\
\hline & Exclusive & Non Exclusive & & & \\
\hline & $\begin{array}{l}\text { Breastfeeding } \\
(\mathrm{N}=179)\end{array}$ & $\begin{array}{l}\text { Breastfeeding } \\
\quad(\mathbf{N}=\mathbf{2 2 1})\end{array}$ & & & \\
\hline \multicolumn{6}{|l|}{ Mother's } \\
\hline \multicolumn{6}{|l|}{ Age } \\
\hline$<20$ & $13(7.3)$ & $16(7.2)$ & & & \\
\hline $21-25$ & $43(24)$ & $55(25.9)$ & & & \\
\hline $26-30$ & $62(34.6)$ & $76(35.8)$ & 0.3727 & 3 & 0.9458 \\
\hline $31-35$ & $49(27.4)$ & $46(21.6)$ & & & \\
\hline $36-40$ & $12(6.7)$ & $28(13.2)$ & & & \\
\hline \multicolumn{6}{|l|}{ Level of } \\
\hline \multicolumn{6}{|l|}{ Education } \\
\hline Non Formal & $6(3.4)$ & $9(4.1)$ & & & \\
\hline Primary & $12(6.7)$ & $16(7.2)$ & & & \\
\hline Secondary & $43(24)$ & $66(29.8)$ & 30.247 & 3 & $<0.001$ \\
\hline Tertiary & $118(65.9)$ & $130(58.8)$ & & & \\
\hline \multicolumn{6}{|l|}{ Occupation } \\
\hline Housewife & $97(54.1)$ & $82(37.1)$ & 6.284 & 1 & 0.0122 \\
\hline Working & $84(46.9)$ & 137 (61.9) & & & \\
\hline \multicolumn{6}{|l|}{ Class } \\
\hline \multicolumn{6}{|l|}{ Parity } \\
\hline 1 & $41(22.9)$ & $35(15.8)$ & & & \\
\hline 2 & $55(30.7)$ & $88(39.8)$ & 17.24 & 2 & 0.0002 \\
\hline$>3$ & $83(46.3)$ & $98(44.3)$ & & & \\
\hline
\end{tabular}

Results from table 3 show the breastfeeding pattern according to the mothers' socio demographic characteristics. The results show that out of 29 mothers aged less than 20 years, $13(7.3 \%)$ breastfed their child exclusively while $16(7.2 \%)$ did not breastfeed exclusively. Of the 98 mothers who were between 21-25 years of age, 43 (24\%) breastfed their children exclusively while $55(24.9 \%)$ did not breastfeed their children exclusively. Of the 138 mothers that were aged 26-30 years, $62(34.6 \%)$ gave exclusive breastfeeding while 76 (34.4\%) did not breastfeed their children exclusively. 95 mothers were aged between 31-35 years of age, $49(27.4 \%)$ breastfed their children exclusively while 46 (20.8\%) did not breastfeed their children exclusively. Out of 40 mothers who were aged 36-40 years, 12 $(6.7 \%)$ breastfed their children exclusively while 28 (12.7\%) did not breastfed their children exclusively.

The results also show that out of 15 mothers who had no formal education, 6 (3.4\%) breastfed their children exclusively while $9(4.1 \%)$ did not breastfeed exclusively. Of the 28 mothers who had primary education, $12(6.7 \%)$ breastfed their children exclusively while $16(7.2 \%)$ 
did not breastfeed exclusively. Out of 109 mothers who completed their secondary education, $43(24 \%)$ breastfed their children exclusively while $66(29.8 \%)$ did not breastfeed exclusively. Finally, 248 mothers had tertiary education and out of this number, $118(65.9 \%)$ breastfed their children exclusively while 130 (58.8\%) did not breastfeed exclusively.

Data on the mothers' occupation showed that 179 mothers were housewives while 221 were working class women. Of the 179 who were housewives, 97 (54.1\%) breastfed their children exclusively while $82(37.1 \%)$ did not breastfeed exclusively. Out of 221 mothers who were working, $84(46.9 \%)$ breastfed their children exclusively while 137 (61.9\%) did not breastfeed exclusively. Concerning the parity of the mothers, 76 had one child; out of this number, $41(22.9 \%)$ breastfed their children exclusively while $35(15.8 \%)$ did not breastfeed exclusively. Of 143 mothers who had up to two children, 55 (30.7\%) breastfed their children exclusively while $88(39.8 \%)$ did not breastfeed exclusively. 181 mothers had three or more children and of this number, $83(46.3 \%)$ breastfed their children exclusively while $98(44.3 \%)$ did not breastfeed exclusively.

Objective 2: Identify the influence of infant related variables on the pattern of breastfeeding of infants aged 0-6 months in Nnamdi Azikiwe University Teaching Hospital Nnewi, Anambra State.

Table 4: Birth related characteristics of the infants according to their breastfeeding groups

\begin{tabular}{|c|c|c|c|c|c|}
\hline \multirow[t]{3}{*}{ Parameters } & \multicolumn{2}{|c|}{ Breastfeeding pattern } & \multirow[t]{3}{*}{$\mathbf{X}^{2}$} & \multirow[t]{3}{*}{ Df } & \multirow[t]{3}{*}{ P-value } \\
\hline & Exclusive & Non Exclusive & & & \\
\hline & Breastfeeding $(N=179)$ & Breastfeeding $(\mathrm{N}=221)$ & & & \\
\hline \multicolumn{6}{|l|}{$\begin{array}{l}\text { Gender of } \\
\text { the baby }\end{array}$} \\
\hline Male & $68(37.9)$ & $120(56.6)$ & & & \\
\hline Female & $111(62)$ & $101(47.6)$ & 0.01483 & 1 & 0.9031 \\
\hline \multicolumn{6}{|l|}{$\begin{array}{l}\text { Baby's } \\
\text { current age }\end{array}$} \\
\hline 0-2 months & $67(37.4)$ & $52(24.5)$ & & & \\
\hline 3-4 months & $62(34.6)$ & $68(32)$ & & & \\
\hline 4-6 months & $50(27.9)$ & $101(47.6)$ & 4. 324 & 2 & 0.8011 \\
\hline \multicolumn{6}{|l|}{$\begin{array}{l}\text { Mode of } \\
\text { delivery }\end{array}$} \\
\hline $\begin{array}{l}\text { Normal } \\
\text { delivery }\end{array}$ & $160(89.3)$ & $149(70.2)$ & & & \\
\hline $\begin{array}{l}\text { Caesarean } \\
\text { section }\end{array}$ & $19(10.6)$ & $72(33.9)$ & 5.804 & 1 & 0.0160 \\
\hline \multicolumn{6}{|l|}{$\begin{array}{l}\text { Place of } \\
\text { delivery }\end{array}$} \\
\hline $\begin{array}{l}\text { Government } \\
\text { Health } \\
\text { facility }\end{array}$ & $171(95.5)$ & $184(83.2)$ & 6.284 & 1 & 0.0122 \\
\hline $\begin{array}{l}\text { Private } \\
\text { Health } \\
\text { facility }\end{array}$ & $8(4.5)$ & $37(16.7)$ & 14.136 & 1 & 0.0002 \\
\hline 77 & & $\begin{array}{l}\text { Article DOI: } 10.52589 / A J H N N \\
\text { OOI URL: https://doi.org/10.52 }\end{array}$ & $\begin{array}{l}\text { P79U9MFY } \\
\text { 89/AJHNM }\end{array}$ & & MFY \\
\hline
\end{tabular}


Table 4 shows the birth related characteristics of the infants according to their breastfeeding groups. The result showed that 188 babies were males while 212 were females. Out of the 188 male babies, 68 (37.9\%) were breastfed exclusively while 120 (56.6\%) were not breastfed exclusively. For the 212 female babies, $111(62 \%)$ were breastfed exclusively while $101(47.6 \%)$ were not exclusively breastfed. Of 119 infants who are aged 0-2 months, 67 (37.4\%) were breastfed exclusively while $52(24.5 \%)$ were not breastfed exclusively. Out of the 130 infants who are aged 3-4 months, 62 (34.6\%) were breastfed exclusively while 68 (32\%) were not breastfed exclusively. For the 151 infants who are aged 4-6 months, 50 $(27.9 \%)$ were breastfed exclusively while $101(47.6 \%)$ were not exclusively breastfed.

Data on mode of delivery showed that 309 babies were delivered normally while 91 were delivered through caesarean section. Out of the 309 normal delivery babies, $160(89.3 \%)$ were breastfed exclusively while $149(70.2 \%)$ were not breastfeed exclusively. For the 91 babies delivered through caesarean section, 19 (10.6\%) were breastfed exclusively while 72 (33.9\%) were not exclusively breastfed. Concerning their place of delivery, 345 babies were delivered in a government health facility while 55 babies were delivered in a privately owned health facility. Out of the 345 babies, 171 (95.5\%) were breastfed exclusively while 184 $(83.2 \%)$ were not exclusively breastfed. For the 45 babies delivered in a private health facility, $8(4.5 \%)$ were breastfed exclusively while $37(16.7 \%)$ were not exclusively breastfed.

This result shows that babies' gender possesses no significant effect on breastfeeding patterns for over 6 months. Place of delivery revealed a significant difference between the two groups. Exclusive breastfeeding was observed in $95.5 \%$ babies delivered in government health facilities compared with $4.5 \%$ delivered in the private health facilities. Only $10.6 \%$ of babies delivered by cesarean section were exclusively breastfed.

Objective 3: To find out the factors that discourage mothers from practicing exclusive breastfeeding.

Table 5: Factors that prevents mother from practicing only EBF

\begin{tabular}{|c|c|c|c|}
\hline & Frequency & Percent & Total (\%) \\
\hline \multicolumn{4}{|c|}{$\begin{array}{l}\text { What prevents you from practicing } \\
\text { only EBF }\end{array}$} \\
\hline Finance & 36 & 16.3 & \\
\hline Personal reasons & 51 & 20.1 & \\
\hline Time & 72 & 32.6 & \\
\hline Dissatisfaction & 40 & 18.0 & \\
\hline Pain & 6 & 2.7 & $221(100)$ \\
\hline Stress & 9 & 4.0 & \\
\hline Baby's refusal & 7 & 3.2 & \\
\hline
\end{tabular}

Table 5 shows the factors that prevented mothers from practicing exclusive breastfeeding. The respondents show that $36(16.3 \%)$ were as a result of finance, $51(20.1 \%)$ were as a result of personal reasons, $72(32.6 \%)$ said it was as a result of time factor, $40(18.0 \%)$ said it was a 
result of dissatisfaction, $6(2.7 \%)$ a result of pains, $9(4.0 \%)$ a result of stress, and $7(3.2 \%)$ said it was a result of the baby's refusal.

\section{DISCUSSION}

The study revealed that the majority (34.5\%) of the mothers were aged 26-30 years, most, $248(62 \%)$ had tertiary education while $57.3 \%$ were among the working class and $45.3 \%$ had three or more children. On the other hand, 53\% were females while $188(47 \%)$ were males. $77.3 \%$ of the babies were delivered through normal delivery while $86.3 \%$ of the babies were delivered at government health facilities. The respondents' pattern of breastfeeding showed that $44.7 \%$ of the babies were exclusively breastfed while more than half $(55.3 \%)$ were not exclusively breastfed. This does not reflect a positive impact of the Baby Friendly Hospital Initiative (BFHI) programmeand the nutrition education given to mothers during their antenatal clinic days. Majority (34.5\%) of the mothers aged 26-30 years practiced exclusive breastfeeding. This could be due to their willingness to heed to the advice of the health workers. A greater number of the mothers had tertiary education. This shows that maternal empowerment made a great contribution to their choice of breastfeeding. The category of mothers who are housewives highly practiced exclusive breastfeeding while many of the working class mothers stopped exclusive breastfeeding earlier. This was attributed to the short duration of maternity leave ( $3 \frac{1}{2} 2$ months post partum).

This study result is consistent with the findings of Kamudoniet al. (2015) that exclusive breastfeeding (EBF) for up to 6 months was practiced by $13.1 \%$ semi-urban and $1.3 \%$ rural mothers. It contradicts the report of Sholeye et al. (2014) that the modal age group of respondents was 30-39 years. This study also contradicts the report of Chauhanet al. (2015) who reported that at birth, $96.67 \%$ infants were exclusively breastfed and the rate was declining progressively up to $23.33 \%$ at 24 weeks of age.

\section{The influence of mothers' socio-demographic variables on the pattern of breastfeeding of infants aged 0-6 months in Nnamdi Azikiwe University Teaching Hospital Nnewi, Anambra State}

The result of this study showed that maternal education reveals a significant effect on their exclusive breastfeeding pattern $(\mathrm{P}<0.05)$ as $65.9 \%$ of mothers who breastfed exclusively had up to tertiary education. This established the fact that maternal education greatly influences decisions on exclusive breastfeeding. This finding corroborates the findings of Jessri, Farmer, Maximova, Willows and Bell (2013) which showed that $41.3 \%$ of women with postgraduate degree exclusively breastfed their infants for up to 6 months whereas only $17.4 \%$ mothers with less than secondary education breastfed their infants for up to 6 months. The low level of education as observed in this present study has potential negative and indirect effects on the breastfeeding pattern and overall improvement of the socio-economic conditions as $29.8 \%$ mothers with less than secondary education breastfed their infants exclusively. Low level of education is also associated with indirect effects of the understanding of nutrition and food aspects as well as improvement of socio-economic conditions (Mosha \& Philemon, 2010). The Tanzania Health Survey (TDHS, 2010) report showed the likelihood of children being fed appropriately increases with mother's education. 
In this study also, an association was found between the parity of mother and breastfeeding practices. This is because $46.3 \%$ of mothers who had three or more children breastfed their children exclusively. The finding is also in line with a study conducted in Saudi Arabia that revealed that $80.6 \%$ multiparous mothers breastfed exclusively compared with $45.7 \%$ nulliparous mothers. It may be because, over the period of time, mothers acquire experience and confidence in proper child care practices such as breastfeeding. This is supported by a report that older women probably know more about the benefits of breastfeeding and have more realistic outcome expectations than younger women (Mansi et al., 2015).

It was also observed in this study that mothers who belong to the working class and formally employed indicated that the frequency and duration of breastfeeding were affected as work conditions were not always conducive for optimal breastfeeding. Similar observation was made in Malta by Montalto et al. (2010) that a general lack of support for breastfeeding in the workplace made many women stop exclusive breastfeeding. Supportive environment for breastfeeding has been described as a critical determinant for successful breastfeeding after three months or longer (Meek, 2001).

Findings from other studies (Dubois \& Girard, 2003; Millar \& Maclean, 2005; Semenic et al., 2008; Al-Sahab et al., 2010) show that having higher years of education, giving birth at older age, having had previous pregnancies and living with a partner are associated with increased likelihood of a six month exclusive breastfeeding. Thus, it is plausible that background characteristics of mothers constitute the basis for designing interventions that aim to improve the breastfeeding practices.

\section{Identify the influence of infant related variables on the pattern of breastfeeding of infants aged 0-6 months in Nnamdi Azikiwe University Teaching Hospital Nnewi, Anambra State}

The finding of this study shows that babies' gender possessed no significant effect on breastfeeding patterns. This study showed a positive association between place of delivery and breastfeeding practices. Place of delivery revealed a significant difference between the two groups as exclusive breastfeeding was observed in $95.5 \%$ babies delivered in government health facilities compared with $4.5 \%$ delivered at private health facilities. Those babies who were delivered at private health facilities were less likely to receive exclusive breastfeeding than those who were born in government hospitals. A study conducted in Nigeria showed similar results that the rate of exclusive breastfeeding was higher among deliveries in government health facilities than those in private health facilities (Ukaegbu, 2010). This shows the importance of correct information provided by medical and paramedical staff to the women regarding breastfeeding.

In this study also, more mothers who gave birth naturally practiced exclusive breastfeeding compared to mothers following a caesarean section delivery. Only $10.6 \%$ of babies delivered by caesarean section were exclusively breastfed. This finding is similar to studies done in Canada, Nepal, and Ethiopia (Seid, Yesuf \& Koye, 2013; Al-Sahab, Lanes, Feldman \& Tamim, 2010). The effects of caesarean section on maternal and fetal stress response and disrupted lactogenesis especially in the first 12 weeks postpartum, are reported as a cause for unsuccessful first breastfeeding attempts and inability to breastfeed upon leaving the healthcare facility (Hobbs, Mannion, McDonald, Brockway \&Tough, 2016). Earlier discharge from the healthcare facility of mothers who had a vaginal birth and their 
reattachment with families could make the postpartum care smooth and increase chances of exclusive breastfeeding.

\section{To find out the factors that discourage mothers from practicing exclusive breastfeeding}

The study revealed that the majority of the respondents $(65.9 \%)$ strongly agreed that breast milk is the best for the baby while others $(0.8 \%)$ strongly disagreed. However, some factors were found out that prevented mothers from practicing exclusive breastfeeding. The factors as shown by the respondents include finance $36(16.3 \%), 51(20.1 \%)$ were as a result of personal reasons, $72(32.6 \%)$ said they did not have much time as they have to go back to work, $40(18.0 \%)$ said it was a result of dissatisfaction, $6(2.7 \%)$ was a result of pains, 9 $(4.0 \%)$ was a result of stress, and $7(3.2 \%)$ was a result of baby's refusal.

The result of this study is in line with the study carried out by Sholeye, Abosede and Salako (2014) in Sagamu, Southwest Nigeria where about 25\% of the study population were pressured by relatives to stop exclusive breastfeeding. Respondents' educational status $(\mathrm{p}<0.001)$, a feeling that breastfeeding had maternal benefits $(\mathrm{p}=0.044)$, feeling of protection against ovarian cancer $(\mathrm{p}=0.030)$ and nipple retraction $(\mathrm{p}=0.015)$ were associated with the practice of exclusive breastfeeding. Reasons for not breastfeeding exclusively include breast pain, a difficult work schedule, poor partner support and perceived weight loss.

The finding of this study is also in line with another study report on the constraints to exclusive breastfeeding practice by Agunbiade and Ogunleye (2012) which showed the major constraints to exclusive breastfeeding to include the perception that babies will continue to be hungry after breastfeeding (29\%), maternal health problems (26\%), fear of babies becoming addicted to breast milk (26\%), pressure from mother-in-law (25\%), pains in the breast $(25 \%)$, and the need to return to work (24\%). Poor feeding, inadequate support from husband and conflicting positions from significant others were other dominant constraints. It could be concluded from these studies that breastfeeding mothers are faced with multiple challenges as they strive to practice exclusive breastfeeding. Thus, scaling up of exclusive breastfeeding among mothers requires concerted efforts at all levels of the Nigerian society.

\section{CONCLUSION}

The data from this study revealed that the majority of the respondents did not practice exclusive breastfeeding; a good number of them were not really practicing exclusive breastfeeding. Some of the factors or barriers that discourage mothers from practicing exclusive breastfeeding were age, educational level, occupation, personal reasons, dissatisfaction, pain and stress. These in turn affected the nutritional status of the babies. This implies that nurses should intensify nutrition education to mothers in antenatal clinics in both public and private hospitals. This is because the choice of feeding practice depends a great deal on the information received by the mother while still pregnant. There should also be adequate and effective maternity protection measures for all child-bearing working mothers in every sphere of life. These measures include adequate maternity leave (up to 6 months postpartum break), nursing breaks and crèches at work places. The role of the media, both print and electronic, is fundamental in creating awareness and public education on exclusive breastfeeding and the current WHO/UNICEF feeding recommendations that breastfeeding with good nutrition is essential to achieving the UN sustainable development goals. 


\section{REFERENCES}

Agunbiade, O. M. and Ogunleye, V. O. (2012) Constraints to exclusive breastfeeding practice among breastfeeding mothers in southwest Nigeria: implications for scaling up. International Breastfeeding Journal. 7: 5.

Al-Sahab B, Lanes A, Feldman M, Tamim H. (2010). Prevalence and predictors of 6-month exclusive breastfeeding among Canadian women: a national survey. BMC Pediatr. 2010;10:20.

American Academy of Pediatrics. (2005). Policy statement: Prevention of pediatric overweight and obesity. Paediatrics, 112 (2), 424-430.

Balkam, J., Cadwell, K., and Fein, S. (2011). Effect of components of a workplace lactation rogram on breastfeeding duration among employees of a public-sector employer. Maternal and Child Health Journal, 15(5), 677-683.

Centers for Disease Control and Prevention. (2013). Breastfeeding data. Retrieved from http://www.cdc.gov/breastfeeding/data/nis_data/index.htm any exclusive- bf-rate.

Chauhan, M. G., Mehta, D. P, Koria, B., Patel, H. and Singh, M. (2016). Assessment of weight gain pattern of exclusively breastfed and nonexclusively breastfed infants in Bhavnagar city, Gujarat. International Journal of Medical Science and Public Health 5:64-68

Cross-Barnet, C., Augustyn, M., Gross, S., Resnick, A., and Paige, D. (2012). Long-term breastfeeding support: Failing mothers in need. Maternal and Child Health Journal, 16 (9), 1926-1932.

Dudenhausen, J. (2014). Breastfeeding is natural but not always easy: Intervention for common medical problems of breastfeeding mothers - A review of the scientific evidence. Journal of Perinatal Medicine, 42(1), 9-18.

Hobbs, A. J., Mannion, C.A., McDonald, S.W., Brockway, M. and Tough, S. C. (2016). The impact of caesarean section on breastfeeding initiation, duration and difficulties in the first four months postpartum. BMC Pregnancy Childbirth.2016;16:90.'

Jennifer, F., Elaine, B., Athena, S., and Virginia, S. (2013). We only talk about breastfeeding: A discourse analysis of infant feeding messages in antenatal group-based education. Midwifery, 29(5), 425-433.

Jessri, M., Farmer, A.P., Maximova, K., Willows, N.D. and Bell, R.C. (2013). Predictors of exclusive breastfeeding: observations from the Alberta pregnancy outcomes and nutrition study. BMC Pediatr2013;13:77

Nigeria Demographic and Health Survey (2013). National Population Commission Federal Republic of Nigeria Abuja, Nigeria. MEASURE DHS, ICF Macro Calverton, Maryland, USA,

Okolo S, Adewunmi Y, Okonji M. (2009) Current breastfeeding knowledge, attitude, and practices of mothers in five rural communities in the Savannah region of Nigeria. Journal of Tropical Paediatrics, 45, 323-326.

Seid AM, Yesuf ME, Koye D. N. (2013). Prevalence of exclusive breastfeeding practices and associated factors among mothers in Bahir Dar city, northwest Ethiopia: a community based cross-sectional study. International Breastfeeding Journal. 2013;8:14

Sencan, I., Tekin, O., and Tatli, M. M. (2013). Factors influencing breastfeeding duration: A survey in a Turkish population. European Journal of Paediatrics, 172(11), 14591466. 
Sholeye, O. O., Abosede, O. A. and Salako, A. A. (2015). Exclusive Breastfeeding and Its Associated Factors among Mothers in Sagamu, Southwest Nigeria, Journal of Health Science, 5 (2), 25-31. doi: 10.5923/j.health.20150502.01.

Silfverdal, S. (2011). Important to overcome barriers in translating evidence-based breastfeeding information into practice. Acta Paediatrica, 100(4), 482-483.

Stevens, D., Hanson, J., Prasek, J., and Elliott, A. (2008). Breastfeeding: A review of the benefits for American Indian women. The Journal of the South Dakota State Medical Association, 61(12), 448-451.

Thulier, D., and Mercer, J. (2009). Variables associated with breastfeeding duration. Journal of Obstetric, Gynaecologic, and Neonatal Nursing: JOGNN/NAACOG, $38(3), 259-268$.

Ukegbu, A. U. (2010). Breastfeeding pattern, anthropometry and health status of infants attending child welfare clinics of a teaching hospital in Nigeria. South African Journal of Clinical Nutrition 23(4):191-6.

Ukegbu A, Ukegbu P, Onyenoro U, Ubajiaka C (2011) Determinants of breastfeeding patterns among mothers in Anambra State, Nigeria. SAJCH 2011, 5, 112-116.

United Nations Children's Fund (2006). Breastfeeding. Retrieved from http://www.unicef.org/nutrition/index_24824.html

World Health Organization. (2003). Global strategy for infant and young child feeding. Albany, NY: Author.

World Health Organization. (2014). 10 facts on breastfeeding. Retrieved from http://www.who.int/features/factfiles/breastfeeding/en/ 